\title{
Myocardial infarction: a complication of amitriptyline overdose
}

\author{
Hassan Chamsi-Pasha and Peter C. Barnes
}

Department of Medicine, Hope Hospital, University of Manchester Medical School, Eccles Old Road, Salford M6 $8 H D, U K$.

\begin{abstract}
Summary: A 22 year old woman was admitted with amitriptyline overdose. Twenty six hours later she developed acute myocardial infarction. Cardiotoxic effects of tricyclic antidepressants are discussed and the importance of considering myocardial infarction as a complication of tricyclic antidepressant overdose is emphasized.
\end{abstract}

\section{Introduction}

Tricyclic antidepressants (TCA) overdose represents $25 \%$ of serious drug self-poisoning, with an overall mortality rate of up to $10 \% .^{1}$ Evidence of cardiovascular toxicity is present in the majority of TCA overdoses. Although myocardial infarction has been reported in patients receiving therapeutic doses of TCA, ${ }^{2-4}$ it has not, to our knowledge, been reported following TCA overdose. We describe such a case in a young patient.

\section{Case report}

A 22 year old woman was admitted 24 hours after taking $300 \mathrm{mg}$ of amitriptyline and $80 \mathrm{mg}$ of diazepam. Apart from a peptic ulcer she had no history of diabetes or any other illnesses, and she was not on any medication. She had never smoked and there was no family history of ischaemic heart disease.

On admission she was unconscious and restless, the pulse was 130 beats per minute and her blood pressure was $110 / 70 \mathrm{~mm} \mathrm{Hg}$. The heart sounds were normal and she had a soft systolic murmur at the pulmonary area. The pupils were dilated but reactive tolight. Noneurologicallocalizingsigns were noted. The electrocardiogram (ECG) revealed sinus tachycardia and the QRS duration was $84 \mathrm{~ms}$. Two hours later her blood pressure fell to $90 / 60 \mathrm{~mm} \mathrm{Hg}$ and ST segment elevation was noted. A 12 lead electrocardiogram showed changes of an acute anteroseptal myocardial infarction (Figure 1). The PR,

Correspondence: H. Chamsi-Pasha, M.D., M.R.C.P.(U.K.), M.R.C.P.I., King Fahad Armed Forces Hospital, P.O. Box 3838, Jeddah 21481.
QRS and QTc duration remained normal. Serial measurements of creatine kinase (CK), creatine kinase M.B., aspartate aminotransferase (AST) and lactic dehydrogenase (LDH) revealed a classical pattern consistent with acute myocardial infarction (Table I). Two dimensional echocardiography was performed and revealed hypokinesia of the septum. The valves appeared normal and the heart chambers were not dilated.

She regained consciousness 12 hours later but she did not recall having chest pain. She did not have fever or a pericardial rub or gallop rhythm at any stage during admission. Her platelets were normal. The blood sugar was $4.5 \mathrm{mmol} / \mathrm{l}$ and total cholesterol was $4.7 \mathrm{mmol} / \mathrm{l}$. The anti-phospholipid antibody test was not performed. She made an uneventful recovery and was discharged home well. She failed to attend for follow-up.

\section{Discussion}

Cardiovascular effects of TCA overdose are common. The most common abnormalities are sinus tachycardia, prolongation of the PR, QRS and QTc intervals, bundle branch block, arrhythmias, hypotension and cardiac arrest. ${ }^{5}$ These effects are mediated by the anticholinergic properties of the TCA, their ability to potentiate the action of the noradrenaline (which could elicit arrhythmias), their blocking effects of peripheral alpha adrenergic receptors and by their quinidine-like action. ${ }^{1,5}$ The latter two mechanisms can contribute to recumbent hypotension sometimes seen in TCA overdose. Similar to quinidine TCA can cause impaired intracardiac conduction and depression of myocardial

(C) The Fellowship of Postgraduate Medicine, 1988 


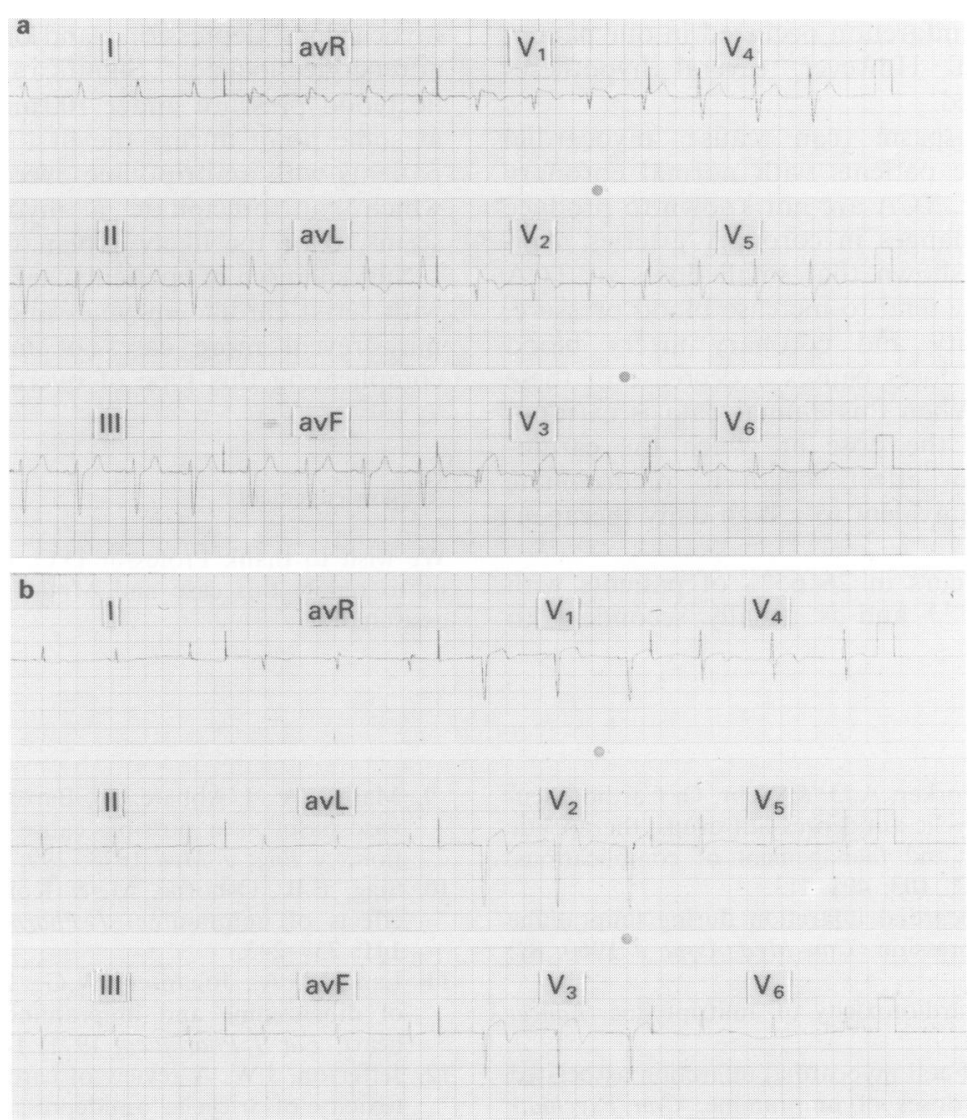

Figure 1 (a) ECG taken 2 hours after admission shows the acute anteroseptal myocardial infarct; (b) ECG taken at 48 hours.

Table I Cardiac enzymes changes consistent with acute myocardial infarction.

\begin{tabular}{|c|c|c|c|c|}
\hline Day & $\begin{array}{cl} & C K \\
\text { (normal } 24-170 I U / l)\end{array}$ & $\begin{array}{c}C K M B \\
(\text { normal }<8 I U / l)\end{array}$ & $\begin{array}{c}A S T \\
\text { (normal 5-45 IU/l) }\end{array}$ & $\begin{array}{c}L D H \\
\text { (normal } 100-225 I U / l)\end{array}$ \\
\hline 1 & 490 & 38 & 258 & 351 \\
\hline 2 & 630 & 54 & 325 & 394 \\
\hline 3 & 110 & 2 & 267 & 333 \\
\hline
\end{tabular}

Day 1 sample was taken 5 hours after admission. Day 2 and 3 samples were performed at 24 and 48 hours later respectively.

contractility. ${ }^{5,6} \mathrm{ST}$ segment elevation resembling that of myocardial infarction has been described following TCA overdose. ${ }^{7}$ Marshall et al. ${ }^{1}$ reviewed four studies including 289 patients who had TCA overdose and no cases of myocardial infarction were found. Cardiac arrest has been reported in up to $12 \%$ of patients in one of these studies ${ }^{8}$ and no post-mortem findings were given. TCA poisoning outcome is unpredictable since severe cardiac com- plications including cardiac arrest have been reported in patients who ingest doses as low as $200 \mathrm{mg}$ of imipramine. ${ }^{8}$

Our patient took only $300 \mathrm{mg}$ of amitriptyline and yet developed acute changes of myocardial infarction 26 hours later. She was unconscious at the time she developed the changes but serial electrocardiograms and cardiac enzymes confirmed the diagnosis. The exact pathogenic mechanism by 
which myocardial infarction occurred in our patient remains uncertain. However, several hypotheses could be postulated.

Coronary vasospasm can cause myocardial infarction in some patients with normal coronary arteries. ${ }^{9}$ However, TCA are not known to produce any vasospastic changes in coronary arteries. Animal studies have shown that small doses of TCA given intravenously tend to increase blood pressure, cardiac contractility and coronary artery blood flow, whilst large doses causes a decrease in these parameters. ${ }^{10.11}$ When this animal data is extrapolated to humans, the dose at which the cardiovascular depressant effects begin to predominate would be about equivalent to a high daily therapeutic dose. ${ }^{12}$

Hypotension occurs in $26-65 \%$ of patients with TCA overdose, ${ }^{13-15}$ and is usually secondary to

\section{References}

1. Marshall, J.B., Forker, A.D. \& Nebr, O. Cardiovascular effects of tricyclic antidepressant drugs: therapeutic usage, overdose, and management of complications. Am Heart $J$ 1982, 103: 401-413.

2. Sloman, L. Myocardial infarction during imipramine treatment of depression. Can Med Assoc J 1960, 82: 20-22.

3. Silverman, G. Cardiotoxicity of amitriptyline. Lancet 1972, ii: 710-711.

4. Goldstein, R.L. Fatal myocardial infarction associated with subclinical doses of imipramine. Can Psychiatr Assoc J 1969, 14: 407-408.

5. Benowitz, N.L., Rosenberg, J. \& Becker, C.E. Cardiopulmonary catastrophies in drug overdosed patients. Med Clin North Am 1979, 63: 267-296.

6. Smith, D.B. \& Tyzink, J.W. Desipramine-induced conduction disorder mimicking myocardial infarction. Postgrad Med 1987, 82: 86-88.

7. Barnes, R.J., Kon, S.M. \& Raymond, W.Y. Electrocardiographic changes in amitriptyline poisoning. $\mathrm{Br}$ Med J 1968, 3: 222-223.

8. Serafimovski, N., Thorball, N., Asmussen, I. \& Lunding, M. Tricyclic antidepressive poisoning with special reference to cardiac complications. Acta Anaesth Scand 1975, 57 (Suppl.): 55-56. myocardial depression and/or peripheral alpha adrenergic blockade. ${ }^{1}$ Significant hypotension (systolic blood pressure under $100 \mathrm{~mm} \mathrm{Hg}$ ) was observed at some point during the first 24 hours in $53 \%$ of patients with amitriptyline overdose. ${ }^{15}$ Hypotension which can precipitate a myocardial infarction ${ }^{16}$ seems to be the likely explanation in our patient.

Surveillance of patients taking TCA overdose with serial cardiac enzymes and electrocardiograms may reveal more cases of myocardial infarction complicating this type of overdose.

\section{Acknowledgements}

We wish to thank Professor D.C. Anderson for allowing us to report this case and Mrs S.A. McGreavy for her assistance.

9. Maseri, A., L'Abbate, A., Baroldi, G. et al. Coronary vasospasm as a possible cause of myocardial infarction. $N$ Engl J Med 1978, 299: 1271-1277.

10. Sigg, E.B., Osborne, M. \& Korol, B. Cardiovascular effects of imipramine. J Pharmacol Exp Ther 1963, 141: $237-243$.

11. Langslet, A., Johansen, W.G., Ryg, M. et al. Effects of dibenzepine and imipramine on the isolated rat heart. Eur J Pharmacol 1971, 14: 333-339.

12. Jefferson, J.W. A review of cardiovascular effects and toxicity of tricyclic antidepressants. Psychosom Med 1985, 37: 160-179.

13. Thorstrand, C. Clinical features in poisoning by tricyclic antidepressants with special reference to the E.C.G. Acta Med Scand 1976, 199: 337-344.

14. Longou, R.A., Van Dyke, C., Tahan, S.R. \& Cohen, L.S. Cardiovascular manifestations of tricyclic antidepressant overdose. Am Heart J 1980, 100: 458-463.

15. Rudorfer, M.V. Cardiovascular changes and plasma drug levels after amitriptyline overdose. $J$ Toxicol Clin Toxicol 1982, 19: 67-78.

16. Cheitlin, M.D., McAllister, H.A. \& de Castro, C.M. Myocardial infarction without atherosclerosis. JAMA 1975, 231: 951-959. 